\title{
II CICLO DE CONFERENCIAS SOBRE URBANISMO EN EL AYUNTAMIENTO DE SEVILLA
}

\author{
71 \\ por \\ María del Carmen Crespo de la Torre
}

En el Ayuntamiento de Sevilla, y continuando con las actividades que viene desarrollando a través del Gabinete de Estudios de su Secretaría General para la formación y perfeccionamiento de sus funcionarios, se ha celebrado, durante los días 24 de noviembre al 12 de diciembre del pasado año 1975, el II Ciclo de Conferencias sobre Urbanismo, que este año ha tenido además la particularidad de estar formalmente patrocinado por el Instituto de Estudios de Administración Local.

El día 24 tuvo lugar la apertura del Ciclo, bajo la presidencia del Alcalde de la ciudad, don Fernando de Parias Merry, y con asistencia de numerosas autoridades y público, pronunciando la conferencia inaugural don Manuel Clavero Arévalo, Catedrático de Derecho Administrativo de la Universidad de Sevilla, que versó sobre «La infracción urbanística grave y manifiesta. Un nuevo concepto al servicio del urbanismo español».

Tras destacar la importancia de las licencias y referirse con extensión al fenómeno del incumplimiento de los Planes de urbanismo, analizando sus causas, examinó el concepto de infracción urbanística grave y manifiesta como nuevo concepto creado por la reforma de la Ley del Suelo; abordando con profundidad la extensa problemática que esta innovación plantea.

Estudió ampliamente las consecuencias de la invalidación de licencia urbanística cuando adolecen de tales infracciones y aludió al tema de la responsabilidad por demora en el otorgamiento de las licencias. Concluyó afirmando que «una civilización como la que nos ha tocado vivir, una civilización urbana, exige de la administración de las ciudades una organización para el urbanismo sumamente competente y actualizada con grandes medios». 
Don Alfonso Pérez Moreno, Profesor Agregado de Derecho Administrativo de la Universidad de Sevilla, pronunció la segunda conferencia del Ciclo, sobre "Urbanismo y desarrollo regional».

Empezó analizando los conceptos de planificación y participación, haciendo constar la importancia que ambos han tenido en la formación del área regional.

Abogó por la existencia de una fórmula regional, que está implícita en la Ley de Bases del Estatuto del Régimen local, y finalizó afirmando que, al amparo de las disposiciones del Plan Nacional de Desarrollo, es posible la creación de Entes regionales descentralizados para la programación y ejecución del desarrollo regional, haciendo alusión en este sentido a la labor llevada a cabo por el Instituto de Desarrollo Regional de la Universidad de Sevilla, creado durante el rectorado del señor Clavero ARÉvalo.

Don Javier Carvajal Ferrer, Doctor Arquitecto, pronunció una conferencia sobre "La reforma de la propiedad del suelo urbano", en la cual puso de manifiesto la dificultad que la misma entraña en unas ciudades ricas en siglos y tradición, si bien se hace necesario que las mismas vayan evolucionando a través del tiempo sin perder su peculiaridad histórica.

Afirmó el señor Carvajal Ferrer que la estructura actual de la propiedad dificulta e imposibilita el proceso de remodelación urbana y de un planteamiento racional de la ciudad con vistas al futuro, pues cada vez que planificamos una barriada social se está pensando en una ciudad sectorizada y antisocial. Ello podría resolverse, en primer lugar, mediante la expropiación o cualquier otra técnica de adquisición por el justo precio; y en segundo lugar, por la expoliación en los sistemas socialistas, afirmando que, a su juicio, existe una tercera vía que consistiría en expropiar el suelo urbano pagando por él su justo precio, no en moneda corriente, sino en una moneda unidireccional de posibilidad de metros cúbicos de construcción, desarrollando ampliamente tan interesante teoría.

Don Rafael de Mendizábal Allende, Magistrado de lo Contencioso-Administrativo del Tribunal Supremo, pronunció su conferencia sobre «La función social de la propiedad».

Empezó el conferenciante haciendo constar la necesidad de adecuar el urbanismo a las nuevas concepciones sociales, considerándolo como un instrumento racional, basado en una auténtica fi- 
losofía social. Dentro del urbanismo convergen factores técnicos y jurídicos utilizados siempre como medios, porque el urbanismo es el eje de la vida colectiva y debe ser enfocado con óptica social.

Seguidamente abordó el concepto de la función social de la propiedad, centrándolo en el binomio derecho-deber de edificar, como eje de ella. Respecto al deber de edificar, el conferenciante examinó la institución del Registro Municipal de Solares, analizando la problemática que plantea, con cita de numerosísimas sentencias recientes y de las más autorizadas opiniones doctrinales.

Terminó diciendo que el Derecho es un instrumento de la Justicia, y el Derecho Administrativo constituye la ecuación del poder y la libertad en un difícil equilibrio. El urbanismo es, además, un concepto esencialmente dinámico que lleva inscrita la idea de cambio social, y el urbanista ha de afrontar la realidad circundante con imaginación creadora para perfeccionarla. Algo muy distinto a la fantasía, sin apoyo en la tierra, flotando entre las nubes, porque el urbanismo auténtico, concluyó, «ha roto siempre los recintos amurallados sin destruir su belleza, para encontrar la belleza de su hora y ensanchar así el horizonte».

El Director del Centro de Estudios Urbanos del Instituto de Estudios de Administración Local, don José Luis GonZález-BERENGUER, disertó sobre «El régimen de las áreas metropolitanas».

Comenzó haciendo constar la doble problemática que el tema implica: De una parte trata de buscar una fórmula de gobierno para las grandes aglomeraciones urbanas, y de otra resolver los problemas que plantea las relaciones entre la gran ciudad y las pequeñas poblaciones que la rodean.

Examinó con amplitud las experiencias existentes en España en las diversas áreas metropolitanas reguladas hasta ahora, resaltando la necesidad de introducir en las mismas un gobierno de doble nivel, suficientemente representativo a la vez que eficaz y coordinado.

Finalmente, abordó con extensión los problemas concretos que plantearía la concepción de Sevilla como Entidad metropolitana, haciendo sugerentes indicaciones prácticas para el futuro de la ciudad.

Don Miguel Cruz Hernandez, Director General de Cultura Popular, clausuró el Ciclo pronunciando una amena conferencia sobre "Los efectos sociológicos del territorio urbano sobre el comportamiento humano». 
Comenzó su disertación considerando al hombre como un ser urbano por naturaleza, poniendo de manifiesto la importancia del habitat en el comportamiento de los animales, avalando esta tesis con múltiples y pintorescos ejemplos. Afirmó a continuación que el hombre, en la actualidad, se encuentra influenciado por dos factores primordiales que inciden de una manera decisiva en su ser y en su comportamiento, cuales son la velocidad y el novedismo.

Se refirió ampliamente a las dos clases de espacios que condicionan el mundo del hombre, el absoluto y el relativo, poniendo de manifiesto que, mediante una oportuna racionalización del mismo, el espacio absoluto de que se dispone sería suficiente, mientras que el espacio relativo que se refiere primordialmente a la relación habitat-vivienda, debe ser remodelado ampliamente. Aboga, finalmente, por la necesidad ineludible de buscar urgentes y eficaces medios que aíslen totalmente las viviendas de las agresiones existentes en los contornos donde las mismas se encuentran ubicadas, haciendo votos porque ese aislamiento con el que utópicamente sueña el hombre se convierta pronto en una palpable realidad.

El Alcalde de Sevilla, don Fernando DE PARIAS MERRY, cerró el Ciclo de estas conferencias pronunciando palabras de agradecimiento a los conferenciantes y al numeroso público que ha asistido al Ciclo.

Puso de relieve, de una manera especial, que las enseñanzas del Ciclo, por su propia naturaleza, estaban destinadas primordialmente a los funcionarios, cuya importancia en la realización y ejecución de un urbanismo eficiente destacó con acertadas palabras.

El Ayuntamiento de Sevilla, al programar estos Ciclos, como los que en lo sucesivo se celebren, sobre éstas u otras materias relacionadas con la Administración municipal, intenta ofrecer un sugerente camino de colaboración con el Instituto de Estudios de Administración Local y con su Escuela Nacional para la formación permanente de sus funcionarios, consciente de que cuanto se haga en este sentido terminará redundando en beneficio de la propia Administración y de los servicios a ella encomendados.

El éxito que estas. conferencias están teniendo entre los propios funcionarios y entre el público en general —debido, sin duda, al prestigio de los conferenciantes que prestan su generosa colaboración-, constituye un elemento esperanzador para continuar en el camino emprendido. Que bien merecería que fuese imitado por otras importantes Corporaciones locales. 


\section{REVISTA}

DE

\begin{tabular}{l} 
ESTUDIOS \\
DE LA \\
DIDA LOCAL \\
\hline
\end{tabular}

\section{ESTADISTICA}


REVL-1976, núm. 189. CRESPO DE LA TORRE, MARIA DEL CARMEN. II CICLO DE CONFERENC...

REVL-1976, núm. 189. CRESPO DE LA TORRE, MARIA DEL CARMEN. II CICLO DE CONFERENC... 